\title{
Article
}

\section{An exploration of the use of Inertial Measurement Units in the assessment of dynamic postural control of the knee and the effect of bracing and taping}

Budini, K, Richards, James, Coles, Thomas, Levine, Rachel, St George, Lindsay Blair and Selfe, James

Available at http://clok.uclan.ac.uk/22480/

Budini, K, Richards, James ORCID: 0000-0002-4004-3115, Coles, Thomas, Levine, Rachel, St George, Lindsay Blair ORCID: 0000-0002-5531-1207 and Selfe, James (2018) An exploration of the use of Inertial Measurement Units in the assessment of dynamic postural control of the knee and the effect of bracing and taping. Physiotherapy Practice and Research, 39 (2). pp. 91-98. ISSN 2213-0683

It is advisable to refer to the publisher's version if you intend to cite from the work. http://dx.doi.org/10.3233/PPR-180111

For more information about UCLan's research in this area go to http://www.uclan.ac.uk/researchgroups/ and search for <name of research Group>.

For information about Research generally at UCLan please go to http://www.uclan.ac.uk/research/

All outputs in CLoK are protected by Intellectual Property Rights law, including Copyright law. Copyright, IPR and Moral Rights for the works on this site are retained by the individual authors and/or other copyright owners. Terms and conditions for use of this material are defined in the policies page. 
An exploration of the use of Inertial Measurement Units in the assessment of dynamic postural control of the knee and the effect of bracing and taping

K. Budini, J. Richards, T. Cole, D. Levine, R. Trede, L St. George, J. Selfe

$5 \quad$ Kristian Budini. PT, Università degli Studi dell'Aquila; budo93@hotmail.it James Richards. PhD, MSc, BEng. University of Central Lancashire; irichards@uclan.ac.uk.

Thomas Cole. BSc. University of Central Lancashire; thomas.cole94@gmail.com Dave Levine. PT, PhD, DPT. The University of Tennessee at Chattanooga; David10 Levine@utc.edu

Renato Trede. PT, M.S., PhD. Universidade Federal dos Vales do Jequitinhonha e Mucuri; renato.trede@gmail.com

Lindsay St. George. PhD. University of Central Lancashire; LBStGeorge@uclan.ac.uk James Selfe. DSc, PhD, MA, GDPhys. Manchester Metropolitan University;

15 i.selfe@mmu.ac.uk

Corresponding Author: James Richards. PhD, MSc, BEng.

Allied Health Research Unit

University of Central Lancashire, Preston, Lancashire PR1 2HE.

$20+44(0) 177289$ 4575. jichards@uclan.ac.uk.

Word Count: 3106

Acknowledgements: none declared. 
Background: The Star Excursion Balance Test (SEBT) is a common clinical test that can provide information about dynamic movement, but does not reflect movement quality or postural-control strategies, and does not report kinematics of the lower limb.

Purpose: To assess the dynamic postural control of healthy subjects using inertial measurement units (IMUs) and clinical SEBT scores to determine the effect of knee bracing and taping.

Methods: Twenty-four healthy individuals performed the SEBT under three randomised conditions (patellar bracing, patellar taping, and control condition (no intervention). Clinical SEBT scores were recorded and normalised to leg length and angular velocities were measured using IMUs during SEBT. Composite scores were calculated as the sum of clinical scores in each direction divided by three. Descriptive statistics (mean $\pm \mathrm{sd}$ ) were calculated for each variable and repeated measures ANOVA were used to identify differences between limb (dominant, non-dominant) and condition.

Main Results: Compared to the control condition, bracing and taping significantly improved dynamic postural control in the sagittal plane by $6 \%(1.5-10.5 \%) \mathrm{P}=0.011$ and $8 \%(2.9-13 \%) \mathrm{P}=0.004$ respectively. Bracing significantly improved coronal plane stability compared to the control condition by $9 \%(3.8-14.1 \%) \mathrm{P}=0.002$, and taping by $7 \%$ (1.612.6\%) $P=0.013$. SEBT scores revealed small but statistically significant differences $(\mathrm{P}<0.05)$ between conditions in the anterior, posteromedial and composite scores, all showing a difference of between $1-2 \%$. 
Principal Conclusions: Patellar soft bracing and taping can improve dynamic postural stability during SEBT. It is possible to detect clinically important changes in lower limb stability from angular velocity using IMUs.

Key Words: Star Excursion Balance Test; Inertial Measurement Unit; Reaction Brace; McConnell 50 Tape.

55 


\section{INTRODUCTION}

65 Patellar bracing and taping techniques are commonly used as conservative therapeutic interventions for the treatment of patellar injury and/or disease [1]. Prophylactic knee braces are commonly used for the prevention of injuries and have been shown to reduce pain, increase knee stability and enhance proprioception [2, 3]. However, their effectiveness on performance in athletic subjects is still controversial [4]. This may be associated with concerns of decreased or impaired athletic performance, which has led to poor compliance [5]. Further research is therefore required to investigate the efficacy of conservative interventions for preventing patellar injury in the non-injured population.

Research has been conducted to investigate the efficacy of various commerciallyavailable patellar bracing products. However, new products and designs are continuously

75 released. Of these, the Reaction Brace (DJO Inc., USA) represents a novel proprioceptive knee brace that it is claimed has a shock absorbing elastomeric design [6], which has been shown to reduce knee pain, increase function and enhance quality of life in patients with patellofemoral pain syndrome (PFP) [6]. The Reaction Brace is described as being useful for the treatment and prevention of various forms of patellar injury and disease, with a recent study describing effects that could also benefit individuals who have suffered an ACL injury [7].

A review, which examined patellofemoral joint treatment modalities, revealed that, research investigating the efficacy of patellar bracing interventions was limited in comparison to the more popular technique of patellar taping [8]. Most notably, the 85 McConnell patellar taping is often employed in clinical practice $[9,10]$ and many studies 
have shown positive effects on pain relief in patients with PFP [11 - 14]. However, the mechanisms for these observed improvements in pain and function in PFP patients are still debated $[10,14,15]$.

Clinicians often employ static postural control assessments to evaluate the effectiveness 90 of an intervention or injury risks and functional deficits [16]. However, dynamic posturalcontrol assessments have been described as advantageous as they better mimic physical activity demands [16]. The Star Excursion Balance Test (SEBT) represents a dynamic postural control assessment, which has been described as a reliable, sensitive and costeffective technique. The SEBT provides an objective method for the evaluation and 95 prediction of dynamic postural control in relation to lower extremity injury and fatigue [16], and has been described as being sufficiently physically demanding for assessing dynamic postural control, as participants must balance on a single limb, whilst the other limb performs maximal reach in different directions [17]. This test has also used to evaluate the effectiveness of interventions and/or training programs in both healthy and injured participants. Herrington [18] used the SEBT to detect performance deficits in ACL and PFP patients compared to healthy volunteers. However, to the author's knowledge, no study has employed the SEBT to evaluate and compare the effects of patellar bracing and taping interventions.

Due to their compact size, user-friendliness and portability, IMUs are gaining popularity 105 in the field of human biomechanics. However, to date, no known studies have used this wearable technology to examine dynamic postural control during the SEBT. The aim of this study was to explore the use of IMUs during SEBT and to gain a further understanding 
of the effects of bracing and taping interventions on knee stability during dynamic postural control.

\section{METHODS}

\section{$\underline{\text { Design }}$}

An exploratory study comparing stability during dynamic postural control (SEBT) on dominant and non-dominant limbs with McConnell taping, bracing and no intervention in healthy individuals using IMUs.

\section{Setting}

Research was conducted in the Movement Analysis Laboratory at the University of Central Lancashire (Preston, UK).

\section{$\underline{\text { Participants }}$}

Twenty-four healthy individuals (13 males, 11 females) from a staff and student 120 population were recruited for the study (age $=22.5 \pm 2.7$ years, height $=171.0 \pm 8.4 \mathrm{~cm}$, mass $=70.6 \pm 13.2 \mathrm{~kg}$, Body Mass Index $\left.=24.1 \pm 3.8 \mathrm{~kg} / \mathrm{m}^{2}\right)$. Eligibility criteria were: 18 to 60 years of age, no history of surgery to the lower extremities 3 months prior to the study, and free from: musculoskeletal or traumatic injuries, neurologic or balance disorders, medical conditions that could limit physical activity, and allergies to tape. All

125 participants were provided with, and read, a detailed explanation of study procedures prior to the study. Written informed consent was obtained from all participants. This study was conducted in accordance with the principles of the Declaration of Helsinki and was approved by the STEMH Ethics Committee of the University of Central Lancashire. 


\section{Materials}

130 Delsys Trigno IM sensors (Delsys Inc., Boston, USA) were bilaterally attached to the skin, $4 \mathrm{~cm}$ above the lateral malleoli (Figure 1). Prior to application, skin was cleaned using Cutisoft wipes (BSN medical GmbH, Hamburg, Germany) to ensure optimal adhesion of IMUs during testing.

\section{Procedure}

135 Participants were instructed to wear shorts and a T-shirt for testing. Limb dominance was determined for each participant as the preferred leg used to kick a ball. Dominant and non-dominant limb were recorded for each participant. Leg length was measured as the distance from the anterior superior iliac spine to the ipsi-lateral medial malleolus in the supine position. Any asymmetries were recorded. Activities of daily living were assessed using the International Physical Activity Questionnaire-Short Version (IPAQ) [19].

Three repetitions on each leg were tested under three randomized conditions no intervention (control), patellar taping and patellar bracing. Data from each participant were collected in a single testing session. For the patellar taping condition, an appropriately trained qualified physiotherapist (KB) applied tape using the medial glide technique

145 established by McConnell [9]. To protect the skin, two strips of Hypafix tape, $50 \%$ of the knee circumference (BSN medical GmbH, Hamburg, Germany), were applied to the knee from the lateral femoral condyle to the medial femoral condyle, covering the height of the patella and ensuring that the area over the hamstrings was not taped [1]. No compression, tension or medial force was applied during this phase. Three "active" rigid strips of 150 Leukotape P (BSN medical GmbH, Hamburg, Germany), were then applied over the 
protective tape, anchoring from the lateral femoral condyle and ending on the medial femoral condyle. These strips were used to produce a medial glide across the patella by pushing medially lightly with the physiotherapist's thumb creating a few creases in the subjects' skin (Figure 1). For the knee brace condition, an off the shelf brace (Reaction 155 Brace, DJO Global Inc.), was applied in accordance with the manufacturer's instructions by the same physiotherapist (Figure 2).

\section{Insert Figure 1.}

The modified Star Excursion Balance Test (SEBT) was used to assess participants' stability and performance in three directions: anterior (A), posteromedial (PM) and 160 posterolateral (PL) [16]. The laboratory floor was marked with three strips of tape that intersected in the center and were oriented at $45^{\circ}$ increments in each direction (Figure 2). Prior to each SEBT test session, a qualified physiotherapist (KB) described the SEBT procedure and instructed participants on how to perform the test correctly. Four practice trials for each leg were permitted prior to data collection [20]. The SEBT was performed 165 barefoot for all conditions.

\section{Insert Figure 2.}

Participants were instructed to fix their hands on their hips and attempt to maintain the same conditions of balance and stability for the duration of the SEBT. The starting position was bilateral stance in the middle of the grid with the great toe of the stance leg placed on the centre point of the strips. Participants were asked to perform maximal reach with their non-stance limb along the each designated direction, always in the same consecutive order: A, PM, PL for both the dominant and non-dominant limbs. The trial 
was concluded following PL reach, when the participant returned to the bilateral stance starting position.

175 During the SEBT, the same researcher measured the distance of each maximal reach from the centre point of the grid to the furthest horizontal projection of the reach foot in each direction. To facilitate this, the grid was created using three plastic tape measures as strips. The researcher manually recorded maximal reach distances for each direction. To mitigate errors in IMU data, touchdown of the extended foot was not permitted [21], as the support gained can widen the base of support [20]. Trials were discarded and repeated if the participant: (1) lost balance during any point of the trial, (2) failed to keep the hands on the hips or (3) moved any part of the stance (test) foot. IMU data were collected throughout the SEBT using EMGworks (Delsys Inc., Boston, USA) software at $148 \mathrm{~Hz}$.

\section{Data Analysis}

Gyroscope (angular velocity) data were exported from EMGworks (Delsys Inc., Boston, USA) software to c3d format and imported into Visual3D (C-Motion Inc. USA) files. Data were filtered using a Butterworth $4^{\text {th }}$ order low-pass filter with a cut-off frequency of 10 $\mathrm{Hz}$. The average range of angular velocity from the three repetitions for sagittal, coronal and transverse plane were analyzed from the stance limb between the events of toe off and toe contact of the non-stance limb for the three conditions. Clinical scores were defined as maximal reach distance in each of the three directions and were normalized to leg length. A composite score was calculated as the sum of normalized reach distances from each direction, divided by three [21, 22]. 
195 Statistical Analysis.

A $2 \times 3$ repeated measures ANOVA was used to investigate differences in clinical and IMU data between limbs (dominant and non-dominant) and conditions. Least significant difference (LSD) pairwise comparisons were used to investigate main effects between limbs and conditions. Effect sizes were calculated using partial eta ${ }^{2}$.

\section{RESULTS}

All participants completed the SEBT without experiencing fatigue and none of the interventions resulted in any adverse reactions. The IPAQ revealed that 12 participants were categorized as high level activity, 9 as medium activity and 3 as low level activity. Mean \pm sd values and ANOVA results for angular velocity data under each of the three 205 conditions are presented in Table 1. Statistical analysis revealed significant differences and a medium effect size for range of angular velocity in the coronal plane $(p=0.003$, $\left.\mathrm{p \eta}^{2}=0.42\right)$ and sagittal plane $\left(\mathrm{p}=0.009, \mathrm{p \eta}^{2}=0.36\right)$ between conditions.

Insert Table 1.

For the SEBT clinical scores, ANOVA showed significant differences between conditions 210 in the anterior $\left(p=0.028, \mathrm{p}^{2}=0.27\right)$ and posteromedial $\left(\mathrm{p}=0.010, \mathrm{p}^{2}=0.18\right)$ directions (Table 2). No significant differences were found between conditions in the posterolateral direction $\left(p=0.513, p \eta^{2}=0.029\right)$. However, significant changes $\left(p=0.04, p \eta^{2}=0.21\right)$ were seen in the composite score.

Insert Table 2. 
215 Further pairwise comparisons presented in Table 3 showed that, in comparison to the control condition, bracing and taping conditions significantly reduced range of angular velocity in the sagittal plane by $6 \%(p=0.011)$ and $8 \%(p=0.004)$, respectively. The bracing condition also reduced range of angular velocity in the coronal plane by $9 \%$ compared to the control $(p=0.002)$ and $7 \%$ taping $(p=0.013)$ conditions. For the clinical score a reduced

220 anterior reach was seen for the taping condition with a small but significant decrease in score of $1 \%$ when compared to the control condition $(p=0.009)$. This effect was also seen for posteromedial reach, which showed a similar small, but significant decrease of $1 \%$ when compared to the control and bracing condition ( $p=0.001, p=0.039)$, respectively. The composite score, pairwise comparisons showed a significant $1 \%$ decrease for the 225 taping condition compared to the control condition $(\mathrm{p}=0.002)$ and a $1 \%$ decrease in score when comparing bracing to the control condition $(\mathrm{p}=0.036)$ (Table 2). In addition, a significant difference was seen between dominant and non-dominant limbs for anterior reach clinical score $(p=0.041)$, with the dominant leg exhibiting a $1 \%$ lower score in than the non-dominant leg.

Insert Table 3.

\section{DISCUSSION}

\section{$\underline{\text { Clinical scores }}$}

The taping intervention produced a small (1\%), but significant reduction in anterior, posteromedial directions and overall composite score compared to the control condition.

235 These findings are in agreement with Aminaka and Gribble [11] and confirm that patellar taping in healthy individuals can significantly reduce reach scores. However, it is 
important to differentiate between statistical and clinical significance. The current study reported differences that were less than $2.5 \%$ of the limb length (LL). A similar study [11] defined the minimum clinically important change threshold as $5 \% \mathrm{LL}$, which equates to

240 approximately $5 \mathrm{~cm}$ reach difference and can influence most sports' tasks. Following this recommendation, the reduced range of motion observed in this study for taping nor bracing did not result in a clinically important change in participants, of which $85 \%$ were in the high and medium levels of physical activity, as measured by the IPAQ.

\section{Bracing}

245 The brace reduced the range of sagittal plane angular velocity by $6 \%$ compared to control conditions. The bracing intervention was also found to significantly reduce the range of angular velocity in the coronal plane in comparison to control and taping interventions. This is in agreement with previous studies $[1,7]$ that have examined this plane. Although it is argued that only the sagittal plane should be examined for evaluating knee stability,

250 these findings suggest that this may not be valid. Imwalle et al [23] demonstrated that analysis of the coronal plane is sensitive and specific in the prediction of ACL injuries.

Most research has assessed knee angular velocities in the sagittal plane [24 - 26]. However, to the authors' knowledge, Hanzlíková et al [7] is the only other study to consider data from all cardinal planes, which reported that bracing resulted in a significant 255 reduction in angular velocity in the transverse plane. Significant differences were not found for sagittal and coronal planes, which is not in accordance with findings from this study. However, direct comparisons of findings between studies cannot be made due to differences in methods, namely the tasks performed by participants. These findings do 
however; further support the evaluation of angular velocity from all cardinal planes when

260 investigating knee stability.

Stability of the knee joint, through coordination of the neuromuscular system, can be defined as the ability to maintain or control joint movement or position [27]. An intervention, which maintains the reach distances but reduces the range of angular velocity implies increased control and stability [24]. This complex process is coordinated

265 by the central nervous system, which processes sensory inputs [24]. It can therefore be assumed that the brace influences the somatosensory pathways, altering movement control in the sagittal plane during SEBT tasks. These bracing-induced neuromuscular alterations and their importance for knee stability have been previously described by Selfe et al [1], who stated that additional cutaneous stimulation provided by bracing may be a 270 significant factor in enhancing neuromuscular control.

\section{$\underline{\text { Taping }}$}

In accordance with the bracing intervention, taping was also found to significantly decrease range of angular velocity of the shank segment in the sagittal plane by $8 \%$ compared to the control condition. This resulted in overall improvements in movement 275 quality and subsequent knee joint stability during the series of unilateral mini-squats required for the SEBT. Improvements in control from taping interventions have also been described by Selfe et al [1,24], who demonstrated that neutral patellar taping had a significant effect on global control improvements of the whole knee. These findings suggest that, like bracing, taping also modifies cutaneous sensory stimulation, enhancing neuromuscular performance. 
In a similar study, Aminaka and Gribble [11] evaluated the effects of patellar taping during SEBT in individuals with and without PFP. However, in contrast to this study, they found no differences in knee kinematics, but did find that PFP patients exhibited increased clinical scores for the patellar taping intervention compared to control. In addition, Hinman et al [28] showed that taping, applied to modify patella position, could alter magnitude or distribution of patellofemoral joint pressure and may therefore affect the stresses acting on the joint structures. The directional force component applied by the tape, which is absent under the brace condition, may offer a further explanation for the results reported in this study. However, further research is required to support these claims.

\section{Clinical Application of IMUs}

Although clinical SEBT scores can be used to assess overall reach performance, these do not appear to be sensitive enough to detect changes in postural control strategies due to bracing and taping. Kinematic data can offer a quantitative and objective assessment method, which could help clinicians to understand the subtle performance limitations and 295 quality of movement that patients may display during the SEBT. This increased sensitivity may aid the clinician's decision-making process, especially when considering the effectiveness of future treatments or intervention methods. The IMUs employed in this study have been previously validated with respect to reference standard accuracy (stereophotogrammetry) [29]. Previous studies have also reported that these IMUs are suitable for use in routine rehabilitation of the lower limb joints, as the gyroscopes have been shown to demonstrate variations in balance control [30]. It is therefore important for therapists to be aware of, and understand the potential advantages of such technology, which can facilitate sensitive measurements [31]. 
This type of measurement technique, which is generally undertaken using laboratorybased optoelectric and electromagnetic systems, has not previously been feasible for use in everyday clinical work. A recent review by Cuesta-Vargas et al [31] compared the use of IMUs with gold standard laboratory systems such as electromagnetic and video-based optoelectronic systems. This review described laboratory-based systems as being complex and expensive, which underlines the discrepancy with systems employed in clinical settings. In contrast, IMUs were described as being able to bridge the gap between large laboratory-based systems and clinical systems, due to their size and portability. The nature of IMU data analysis often employs biomechanical models. However, in this study, accelerometer and gyroscope data were evaluated through careful placement of the sensors on the shank segment. Findings from this study reveal that these measurements can detect clinically important changes, which occurred when patellar bracing and taping interventions were applied. The clinical and practical applicability IMUs is therefore highlighted in the current study, as data acquisition was guided by a physiotherapist, who was able to collect, process and subsequently interpret IMU data without difficulty.

\section{Limitations}

This study used of a single sensor placed on the left and right shank, however subjects could have adopted different strategies. In addition, the use of a single group of subjects and testing only the immediate effects may also be viewed as limitations of this study.

\section{$\underline{\text { CONCLUSION }}$}

Findings from this study reveal that it is possible to detect clinically important changes in 325 movement quality and postural-control strategies in lower limb stability using IMUs placed 
on the shank of healthy individuals. Results suggest that the use of patellar soft bracing and taping techniques can improve dynamic postural stability during an SEBT test. This suggests that athletes who apply patellar taping or bracing interventions during physical activity are unlikely to experience restrictions in performance. Findings from this study 330 also suggest that coronal and transverse knee kinematics should not be overlooked when evaluating dynamic postural control using the SEBT. 
1. Selfe J, Thewlis D, Hill S, Whitaker J, Sutton C, Richards J. A clinical study of the biomechanics of step descent using different treatment modalities for patellofemoral pain. Gait Posture. 2011;34:92-96.

2. Merrick M. Does patellofemoral bracing work. Athl Ther Today. 2000;9:34-5.

3. Van Tiggelen D, Witvrouw E, Roget P, Cambier D, Danneels L, Verdonk R. Effect of bracing on the prevention of anterior knee pain--a prospective randomized study. Knee Surg Sports Traumatol Arthrosc. 2004;12:434-439.

4. Baltaci G, Aktas G, Camci E, Oksuz S, Yildiz S, Kalaycioglu T. The effect of prophylactic knee bracing on performance: balance, proprioception, coordination, and muscular power. Knee Surg Sports Traumatol Arthrosc. 2011;19:1722-1728.

5. Rishiraj N, Taunton JE, Lloyd-Smith R, Woollard R, Regan W, Clement DB. The potential role of prophylactic/functional knee bracing in preventing knee ligament injury. Sports Med. 2009;39:937-960.

6. Khadavi JM, Chen YT, Fredericson M. A Novel Knee Orthosis in the Treatment of Patellofemoral Pain Syndrome. Open J Ther Rehabil. 2015;3:56-61.

7. Hanzlíková I, Richards J, Tomsa M, et al. The effect of proprioceptive knee bracing on knee stability during three different sport related movement tasks in healthy subjects and the implications to the management of Anterior Cruciate Ligament (ACL) injuries. Gait Posture. 2016;48:165-170.

355 8. Selfe J. The Patellofemoral Joint: A Review of Primary Research. Crit Rev Phys Rehabil Med. 2004;16:1-30. 
9. McConnell J. The management of chondromalacia patellae: a long term solution. Aust J Physiother. 1986;32:215-223

10. Wilson T, Carter N, Thomas G. A multicenter, single-masked study of medial, neutral, and lateral patellar taping in individuals with patellofemoral pain syndrome. $J$ Orthop Sports Phys Ther. 2003;33:437-43-8.

11. Aminaka N, Gribble PA. A systematic review of the effects of therapeutic taping on patellofemoral pain syndrome. J Athl Train. 2005;40:341-351.

12. Powers CM, Landel R, Sosnick T, Kirby J, Mengel K, Cheney A, et al. The effects of patellar taping on stride characteristics and joint motion in subjects with patellofemoral pain. J Orthop Sports Phys Ther. 1997;26:286-91.

13. Whittingham, M., Palmer, S. and Macmillan, F. Effects of taping on pain and function in patellofemoral pain syndrome: a randomized controlled trial. J Orthop Sports Phys Ther. 2004;34:504-510.

14. Callaghan, M.J. Patellar taping, the theory versus the evidence: a review. Phys Ther Rev. 1997;2:181-183.

15. Callaghan MJ, Selfe J, McHenry A, Oldham JA. Effects of patellar taping on knee joint proprioception in patients with patellofemoral pain syndrome. Man Ther. 2008;13:192-199.

16. Gribble PA, Hertel J, Plisky P. Using the Star Excursion Balance Test to assess dynamic postural-control deficits and outcomes in lower extremity injury: a literature and systematic review. J Athl Train. 2012;47:339-357.

17. Olmsted LC, Carcia CR, Hertel J, Shultz SJ. Efficacy of the Star Excursion Balance Tests in Detecting Reach Deficits in Subjects With Chronic Ankle Instability. J Athl 
Train. 2002;37:501-506.

18. Herrington L, Hatcher J, Hatcher A, McNicholas M. A comparison of Star Excursion Balance Test reach distances between ACL deficient patients and asymptomatic controls. Knee. 2009;16:149-152.

19. Kurtze N, Rangul V, Hustvedt B-E. Reliability and validity of the international physical activity questionnaire in the Nord-Trøndelag health study (HUNT) population of men. BMC Med Res Methodol. 2008;8:63.

20. Robinson RH, Gribble PA. Support for a reduction in the number of trials needed for the star excursion balance test. Arch Phys Med Rehabil. 2008;89:364-370.

21. Plisky PJ, Rauh MJ, Kaminski TW, Underwood FB. Star Excursion Balance Test as a predictor of lower extremity injury in high school basketball players. J Orthop Sports Phys Ther. 2006;36:911-919.

22. Plisky PJ, Gorman PP, Butler RJ, Kiesel KB, Underwood FB, Elkins B. The reliability of an instrumented device for measuring components of the star excursion balance test. N Am J Sports Phys Ther. 2009;4:92-99.

23. Imwalle LE, Myer GD, Ford KR, Hewett TE. Relationship Between Hip and Knee Kinematics in Athletic Women During Cutting Maneuvers: A Possible Link to Noncontact Anterior Cruciate Ligament Injury and Prevention. J Strength Cond Res. 2009;23:2223-2230.

24. Selfe J, Richards J, Thewlis D, Kilmurray S. The biomechanics of step descent under different treatment modalities used in patellofemoral pain. Gait Posture. 2008;27:258-263.

25. Hahn D, Herzog W, Schwirtz A. Interdependence of torque, joint angle, angular 
velocity and muscle action during human multi-joint leg extension. Eur J Appl Physiol. 2014;114:1691-1702.

26. Wang L-I. The lower extremity biomechanics of single- and double-leg stop-jump tasks. J Sports Sci Med. 2011;10:151-156.

27. Prodromos Ch, Brown Ch, Fu FH, Georgoulis AD, Gobbi A HS, Johnson D, Paulos LE SK. The Anterior Cruciate Ligament: Reconstruction and Basic Science. 1st ed. (Philadelphia: Elsevier Saunders, ed.).; 2008.

28. Hinman RS, Crossley KM, McConnell J, Bennell KL. Efficacy of knee tape in the management of osteoarthritis of the knee: blinded randomised controlled trial. BMJ. 2003;327:135.

29. Leardini A, Lullini G, Giannini S, Berti L, Ortolani M, Caravaggi P. Validation of the angular measurements of a new inertial-measurement-unit based rehabilitation system: comparison with state-of-the-art gait analysis. J Neuroeng Rehabil. 2014;11:136.

30. Alberts JL, Hirsch JR, Koop MM, et al. Using Accelerometer and Gyroscopic Measures to Quantify Postural Stability. J Athl Train. 2015;50:578-588.

31. Cuesta-Vargas AI, Galán-Mercant A, Williams JM. The use of inertial sensors system for human motion analysis. Phys Ther Rev. 2010;15:462-473. 


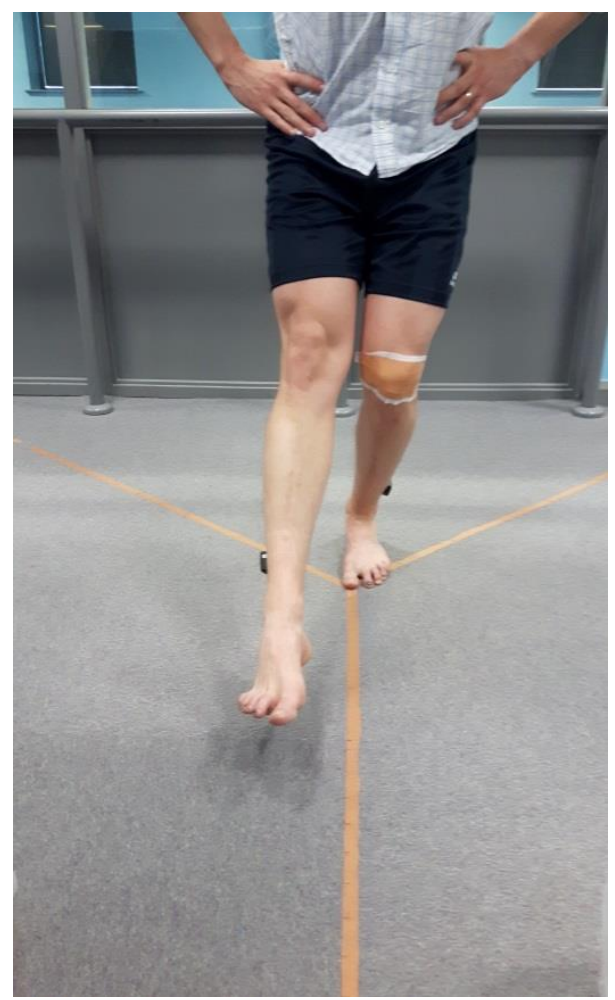

Figure 1. Participant performing the anterior reach of Star Excursion Balance Test (SEBT) under the McConnell tape condition (left leg standing). 


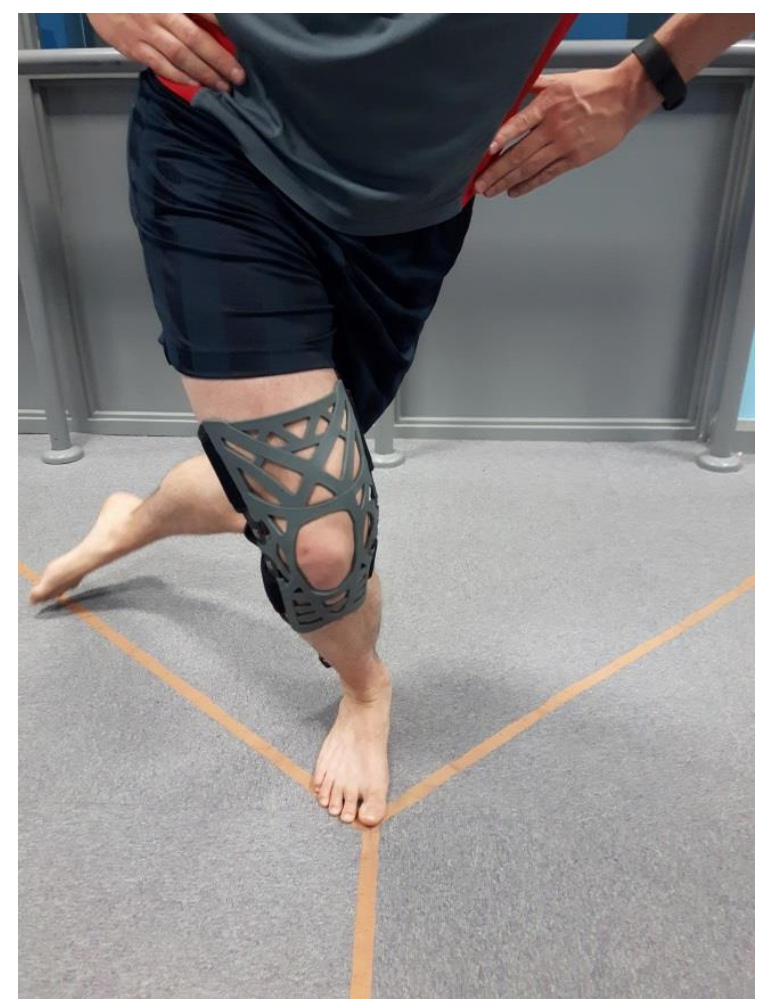

Figure 2. Participant performing the posterolateral reach of Star Excursion Balance Test (SEBT) under the Reaction Brace condition (right leg standing).

375 


\begin{tabular}{|c|c|c|c|c|c|c|}
\hline \multirow[b]{3}{*}{$\begin{array}{c}\text { Condition } \\
\text { (Limb Dominance) }\end{array}$} & \multicolumn{6}{|c|}{ Range of Angular Velocity (deg/s) } \\
\hline & \multicolumn{2}{|c|}{ Sagittal Plane } & \multicolumn{2}{|c|}{ Coronal Plane } & \multicolumn{2}{|c|}{$\begin{array}{c}\text { Transverse } \\
\text { Plane }\end{array}$} \\
\hline & Mean & sd & Mean & sd & Mean & sd \\
\hline B (ND) & 57.5 & 13.9 & 25.3 & 5.3 & 36.9 & 12.3 \\
\hline$C$ (ND) & 62.3 & 15.2 & 28.4 & 7.9 & 38.9 & 17.5 \\
\hline$T$ (ND) & 57.8 & 14.1 & 29.1 & 10.2 & 39.0 & 10.6 \\
\hline$B(D)$ & 57.3 & 16.5 & 25.9 & 6.9 & 37.1 & 13.2 \\
\hline$C$ (D) & 60.0 & 14.7 & 27.9 & 7.2 & 39.8 & 13.1 \\
\hline $\mathrm{T}(\mathrm{D})$ & 54.6 & 14.6 & 27.6 & 7.5 & 37.2 & 13.8 \\
\hline RM ANOVA & P-value & $\mathrm{pn}^{2}$ & P-value & $\mathbf{p n}^{2}$ & P-value & $\mathbf{p n}^{2}$ \\
\hline Condition & $0.009^{\star}$ & 0.36 & $0.003^{*}$ & 0.42 & 0.154 & 0.16 \\
\hline Limb Dominance & 0.355 & 0.04 & 0.680 & 0.01 & 0.837 & 0.002 \\
\hline
\end{tabular}

Table 1: Descriptive and inferential results from ANOVA tests for range of angular velocity. Results are presented for non-dominant (ND) and dominant (D) limbs, and for bracing $(\mathrm{B})$ taping $(\mathrm{T})$ and control $(\mathrm{C})$ conditions. *Significant difference between conditions. 


\begin{tabular}{|c|c|c|c|c|c|c|c|c|}
\hline & \multicolumn{6}{|c|}{ Normalised Maximal Reach Distance (\% leg length) } & \multirow{2}{*}{\multicolumn{2}{|c|}{$\begin{array}{c}\text { Composite score } \\
\text { (\%leg length) }\end{array}$}} \\
\hline & \multicolumn{2}{|c|}{ Anterior Reach } & \multicolumn{2}{|c|}{$\begin{array}{c}\text { Posteromedial } \\
\text { Reach }\end{array}$} & \multicolumn{2}{|c|}{$\begin{array}{c}\text { Posterolateral } \\
\text { Reach }\end{array}$} & & \\
\hline $\begin{array}{c}\text { Condition } \\
\text { (Limb Dominance) }\end{array}$ & Mean & sd & Mean & sd & Mean & sd & Mean & sd \\
\hline B (ND) & 0.658 & 0.057 & 0.891 & 0.077 & 0.869 & 0.103 & 0.806 & 0.069 \\
\hline$C$ (ND) & 0.645 & 0.061 & 0.906 & 0.052 & 0.860 & 0.106 & 0.804 & 0.063 \\
\hline $\mathrm{T}$ (ND) & 0.669 & 0.051 & 0.900 & 0.082 & 0.873 & 0.098 & 0.815 & 0.067 \\
\hline$B(D)$ & 0.655 & 0.066 & 0.905 & 0.064 & 0.871 & 0.081 & 0.812 & 0.056 \\
\hline$C$ (D) & 0.653 & 0.057 & 0.888 & 0.086 & 0.863 & 0.114 & 0.799 & 0.074 \\
\hline$T(D)$ & 0.639 & 0.057 & 0.882 & 0.056 & 0.861 & 0.087 & 0.796 & 0.059 \\
\hline RM ANOVA & P-value & $p \eta^{2}$ & P-value & $p \eta^{2}$ & P-value & $\mathrm{pn}^{2}$ & P-value & $\mathrm{pn}^{2}$ \\
\hline Condition & $0.028^{\star}$ & 0.27 & $0.010^{\star}$ & 0.181 & 0.513 & 0.029 & $0.004^{\star}$ & 0.21 \\
\hline Limb Dominance & $0.041^{*}$ & 0.17 & 0.655 & 0.009 & 0.727 & 0.005 & 0.676 & 0.008 \\
\hline
\end{tabular}

Table 2: Descriptive and inferential results from ANOVA tests for SEBT clinical score.

Results are presented for non-dominant (ND) and dominant (D) limbs, and for bracing (B) taping $(\mathrm{T})$ and control $(\mathrm{C})$ conditions. *Significant difference between conditions. 


\begin{tabular}{|c|c|c|c|c|}
\hline $\begin{array}{l}\text { Range of angular velocity } \\
\text { (deg/s) }\end{array}$ & Comparison & $\begin{array}{c}\text { Mean } \\
\text { Difference }\end{array}$ & $p$-value & $\begin{array}{c}\text { Lower and Upper } \\
95 \% \mathrm{Cl}\end{array}$ \\
\hline \multirow{3}{*}{ Sagittal Plane } & B vs C & $-3.74^{*}$ & 0.011 & $(-6.53,-0.96)$ \\
\hline & $B$ vs $T$ & 1.18 & 0.425 & $(-1.83,4.20)$ \\
\hline & C vs T & $4.93^{*}$ & 0.004 & $(1.80,8.05)$ \\
\hline \multirow{3}{*}{ Coronal Plane } & B vs $C$ & $-2.59^{*}$ & 0.002 & $(-4.07,-1.10)$ \\
\hline & $B$ vs $T$ & $-2.76^{*}$ & 0.013 & $(-4.99,-0.64)$ \\
\hline & C vs T & -0.17 & 0.871 & $(-2.34,1.99)$ \\
\hline \multirow{3}{*}{ Transverse Plane } & B vs C & -3.42 & NS & $(-6.54,0.29)$ \\
\hline & $B$ vs $T$ & -0.50 & NS & $(-3.51,2.51)$ \\
\hline & C vs T & 2.92 & NS & $(-0.86,6.70)$ \\
\hline $\begin{array}{c}\text { Normalized Clinical Score } \\
(\% \text { leg length) }\end{array}$ & Comparisons & $\begin{array}{c}\text { Mean } \\
\text { Difference }\end{array}$ & $p$-value & $95 \% \mathrm{Cl}$ \\
\hline \multirow{3}{*}{ Anterior Reach } & B vs $C$ & -0.010 & 0.057 & $(-0.021,0.000)$ \\
\hline & B vs $T$ & 0.005 & 0.350 & $(-0.006,0.016)$ \\
\hline & C vs T & $0.015^{*}$ & 0.009 & $(0.004,0.027)$ \\
\hline \multirow{3}{*}{ Posteromedial Reach } & B vs C & 0.004 & 0.514 & $(-0.017,0.009)$ \\
\hline & B vs T & $0.013^{*}$ & 0.039 & $(0.001,0.026)$ \\
\hline & $\mathrm{C}$ vs T & $0.018^{*}$ & 0.001 & $(0.008,0.027)$ \\
\hline \multirow{3}{*}{ Posterolateral Reach } & B vs C & -0.008 & NS & $(-0.024,0.009)$ \\
\hline & $B$ vs $T$ & 0.003 & NS & $(-0.020,0.025)$ \\
\hline & $\mathrm{C}$ vs T & 0.008 & NS & $(-0.006,0.027)$ \\
\hline \multirow{3}{*}{ Composite Reach } & B vs C & $-0.009^{*}$ & 0.036 & $(-0.017,0.001)$ \\
\hline & $B$ vs $T$ & 0.008 & 0.172 & $(0.004,0.019)$ \\
\hline & C vs T & $0.016^{*}$ & 0.002 & $(0.007,0.026)$ \\
\hline
\end{tabular}

Table 3: Results from pairwise comparisons between condition and limb dominance.

Results are presented for bracing (B) taping ( $T$ ) and control (C) conditions. Significant differences are presented as bold text. NS = no significant main effect. 